\title{
La comedia de El mejor representante, San Ginés, de J. Cáncer, P. Rosete y A. Martínez de Meneses: un caso ejemplar de metateatralidad
}

\author{
Cáncer, Rosete and Martínez de Meneses' \\ El mejor representante, San Ginés: \\ An Extraordinary Case of Metatheatricality
}

JAVIER RUBIERA

Université de Montréal

Département de littératures et de langues du monde

c.P. 6128 , succursale Centre-ville

Montreal (Quebec) h3c 3jt. Canadá

javier.rubiera@umontreal.ca

Orcid ID 0000-0002-0273-7116

Resumen: Este artículo proporciona una introducción general a una comedia escrita en colaboración por tres poetas e impresa en 1668, que merece mejor conocimiento por parte de la crítica, debido a su extraordinario valor metateatral: El mejor representante, San Ginés. Tras unas observaciones sobre sus rasgos principales (fuente, ediciones y representaciones, recepción crítica, forma y estructura), se profundizará en dos aspectos sobre los que hasta ahora no se había llamado la atención: por un lado, la relevancia de la intervención del peculiar personaje cómico llamado Pocarropa, máscara de un desconocido actor de la época; por otro lado y principalmente, el recurso a la metateatralidad, tan variado, continuo y fértil que incluso va más allá de lo esperable en una comedia que, aunque de carácter hagiográfico, tiene como protagonista a un actor.

Palabras clave: Metateatralidad. Comedias en colaboración. San Ginés. Jerónimo Cáncer. Pedro Rosete. Martínez de Meneses.
Abstract: This article is a general introduction to $E$ I mejor representante, San Ginés, a collaborative play printed in 1668 and written by three poets that deserves better knowledge on the part of the critic, due to its extraordinary metatheatrical value. After some observations on its main features (source, editions and representations, critical reception, form and structure), it focuses on two aspects on which until now the attention has not been called: on the one hand, the relevance of the intervention of a peculiar comic character called Pocarropa, mask of an unknown actor of the time; on the other hand and mainly, the use of metatheatre, so varied, continuous and fertile that it even goes beyond what is expected in a comedy that, although hagiographic, has an actor as its protagonist.

Keywords: Metatheatre. Collaborative Plays. St Genesius. Jerónimo Cáncer. Pedro Rosete. Martínez de Meneses. 
S e han cumplido en 2018 veinticinco años de la publicación del libro de Ann L. MacKenzie La escuela de Calderón: estudio e investigación, en uno de cuyos capítulos se lleva a cabo el primer tratamiento de importancia sobre el procedimiento de colaboración entre varios poetas para la composición de una comedia, desarrollado a partir de la tercera década del siglo XVII. En estos veinticinco años se ha progresado enormemente en el conocimiento de algunas de las comedias "colaboradas", 1 pero queda aún una extraordinaria labor por delante, en primer lugar con la edición y estudio de las piezas en las que no participaron grandes poetas como Luis Vélez de Guevara, Pedro Calderón, Francisco de Rojas Zorrilla y Agustín Moreto, cuyas obras, de modo general y por motivos obvios, han sido las que más atención han recibido hasta ahora.

Este artículo proporciona la introducción general a una comedia escrita por tres ingenios considerados menores y que merece mejor conocimiento por parte de la crítica, debido a su extraordinario valor metateatral. Tras unas observaciones sobre sus rasgos principales (fuente, ediciones y representaciones, recepción crítica, forma y estructura), se profundizará en dos aspectos sobre los que hasta ahora no se había llamado la atención: por un lado, la relevancia de la intervención del peculiar personaje cómico llamado Pocarropa o Pocaropa, máscara de un desconocido actor de la época; por otro lado y principalmente, el recurso a la metateatralidad, tan variado, continuo y fértil que incluso va más allá de lo esperable en una comedia que, aunque de carácter hagiográfico, tiene como protagonista a un actor.

\section{SAN GINÉS EN EL TEATRO}

Es bien sabido que durante los siglos XVI y XVII, siguiendo la senda que procede entre otros de la Leyenda áurea o dorada de Jacobo de la Vorágine, los libros que recopilaban las vidas de santos fueron una lectura extendidísima, fuente de reflexión, de imitación y de devoción. Auténticos éxitos editoriales en castellano supusieron los diferentes tomos del Flos Sanctorum de Alonso de Villegas (1578-1603) así como los posteriores, reeditados en varias ocasiones, del Flos Sanctorum de Pedro de Ribadeneyra (1599-1601-1604), que a su vez

1 Dentro de la ya amplísima bibliografía sobre las comedias en colaboración, ver principalmente el imprescindible estudio de Alviti (con su catálogo descriptivo de comedias) y los trabajos publicados recientemente en las obras editadas por Matas Caballero (2017), y Lobato y Martínez Carro (2018). 
se convirtieron en primera inspiración de numerosas obras escritas para la escena teatral, como Lo fingido verdadero. Esta famosa pieza de Lope de Vega, que gira en torno a la figura legendaria del comediante Ginés de Roma martirizado en tiempos del emperador Diocleciano, ${ }^{2}$ debió componerse en fecha muy cercana a 1609 y fue incluida en 1621 en la Parte XVI de comedias preparada por el propio Lope. En la dedicatoria a Fray Gabriel Téllez se la nombra como "Tragicomedia de la vida y martirio de san Ginés representante" (Vega 56) y en la lista de obras de El peregrino en su patria -la segunda, de 1618como "El mejor representante", lo que coincide con el último verso de la pieza impresa: "Aquí acaba la comedia / del mejor representante" (Vega 160).

Lo fingido verdadero es, pues, una variación dramática sobre la vida, la conversión y el martirio de San Ginés, patrón de los actores, materia que fue abundantemente tratada en la escena europea del siglo XVII en diferentes lenguas: baste recordar en Francia los casos de Nicolas Mary Defontaines (L'Illustre Comédien ou le Martyr de Saint Genest, en 1645) y de Jean Rotrou (Le véritable Saint Genest, 1647) o en Italia el del Ginnesio de Michelangenlo Buonarroti il Giovane, de hacia 1639, y el San Ginnesio de Michele Stanchi, representado en 1687, aparte de las diversas escenificaciones testimoniadas en colegios jesuíticos de Polonia, Austria, Alemania, Suiza ${ }^{3}$ o Francia, donde, por ejemplo, se representa en Anvers en 1641 un Genesius Mimus pro Christo martyr (Rotrou 119). Por su parte, en España hay que señalar que varias décadas después de Lo fingido verdadero subió a las tablas, probablemente en los años cuarenta del XVII, una comedia fruto de la colaboración de tres ingenios titulada El mejor representante, San Ginés. Fue publicada en 1668, en la Parte veinte y nueve de comedias nuevas, escritas por los mejores ingenios de España, en Madrid por Joseph Fernández de Buendía, ${ }^{4}$ donde aparece atribuida a Jeróni-

2 En la obra de Lope, desde su primera intervención Ginés aparece como poeta, actor y autor de comedias. En la de los tres ingenios a la que nos referimos aquí, Ginés es al comienzo soldado y poco después se convierte en actor, profesión para la que parecía estar dotado desde joven (vv. $784-85$ y vv. 2394 y ss.).

3 Tomo estos datos sobre escenificaciones en colegios jesuíticos (Friburgo, Múnich, Kalisz, Constanza, Poznan, Friburgo de Brisgovia, Innsbruck, etc.) de Ursula Aszyck (75), que los toma a su vez de un artículo en polaco de Jan Okon.

4 Citaré fragmentos de la comedia según mi edición inédita a partir del ejemplar digitalizado por la Biblioteca Nacional de España, R.22682. Algunas páginas con impresión más clara de la misma edición de 1668 pueden encontrarse también en otros dos ejemplares de la Parte 29 (sin preliminares) conservados en la BNE, que he consultado para aclarar algunas dudas de lectura: Ti/ 16-29; Ti/ 119.29. Un cuarto ejemplar de la Parte 29 está incompleto (sin preliminares y con solo cinco comedias), aunque contiene también El mejor representante, con la escena final copiada a mano (Ti/146-21), como ocurre en otras partes de este ejemplar mutilado. 
mo de Cáncer, Pedro Rosete y Antonio Martínez [de Meneses], por ese orden. $\mathrm{Al}$ igual que ocurre con Lo fingido verdadero, fuente en la que se inspira, de ella no se conservan ni manuscritos del siglo XVII ${ }^{5}$ ni ediciones sueltas y, según los pocos datos conservados, tuvo un discreto paso por los escenarios, que luego recordaremos.

Lo fingido verdadero es probablemente la comedia religiosa de Lope que más interés ha suscitado entre la crítica en los últimos cuarenta años, pues son muy numerosos los artículos o capítulos de libro que se han dedicado a diferentes aspectos formales y temáticos de la pieza. Entre ellos sin duda destacan aquellos trabajos que reconocen su valor ejemplar como obra bien representativa de la "metateatralidad" en el mundo barroco. En general, aparte de la consideración de los valores de la pieza como comedia religiosa, los críticos han centrado predominantemente su atención en la comparación con otras piezas del XVII que han tratado la figura de San Ginés en el teatro, en aspectos de estética y de teoría teatral vinculados a la doctrina del Arte nuevo de bacer comedias, escrita por el mismo tiempo que el drama, y en profundizar en el análisis de la dimensión metateatral de la obra, que juega de modo maestro con el tópico del "theatrum mundi". Como he sugerido en uno de los artículos que he dedicado a esta pieza de Lope, el interés y el gusto modernos, y postmodernos, encuentran en su metateatralidad el valor primero de una comedia que juega agudamente con diferentes niveles de representación, que nos siguen hablando hoy de la propia inestabilidad del espectáculo de la realidad y de nuestra extraña condición de representantes en el teatro del mundo (Rubiera 2016, 187).

A diferencia de Lo fingido verdadero, la comedia de Cáncer, Rosete y Martínez de Meneses no ha sido convenientemente considerada por la crítica ni los historiadores del teatro han aprovechado la rica información sobre el medio teatral que proporciona. ${ }^{6}$ No contamos con ninguna edición moderna de la

5 En la Biblioteca Nacional de España se conserva un manuscrito (MSS/1644) de dieciséis hojas en tamaño folio, titulado San Ginés, al que no he visto referirse ninguno de los numerosos estudios que tratan obras teatrales sobre el tema de San Ginés. Se trata de una comedia sin nombre de autor, probablemente de finales del siglo XVI o principios del XVII. Actualmente preparo su estudio y edición junto a Alejandro García-Reidy.

6 A pesar de los interesantes datos que, como veremos, contiene en relación con el mundo teatral del siglo XVII, Shergold no la cita en su monumental History ni Oehrlein en su libro sobre el actor en el Siglo de Oro. Rennert solo la aprovecha una vez para ejemplificar, al comienzo del capítulo IX, que los actores eran pagados cada tarde de representación, a no ser que hubiera un acuerdo específico contrario (181). Tampoco es referencia en famosas obras de los siglos XIX y XX que consideran el teatro español desde un punto de vista costumbrista. 
pieza y solo Mariateresa Cattaneo, editora del drama de Lope, le ha dedicado atención y ha mostrado conocerla con cierta profundidad al ponerla en relación con otras comedias que giran en torno a la figura del santo representante, en lo que ha llamado "las transformaciones de Ginés" en la escena europea. Sin embargo, tal como hemos avanzado un poco más arriba, es una comedia que merece más amplio conocimiento, sobre todo por el tratamiento del tema del teatro en el teatro, que aparece ampliamente representado con originalidad en diversas variaciones de gran interés. De tal manera es así que puede considerarse imprescindible en cualquier trabajo de conjunto sobre la metateatralidad y sobre la vida teatral de la España del Siglo de Oro, a pesar de situarse la acción a finales del siglo III, en la época de Diocleciano. Efectivamente, podría decirse que en la comedia se sitúa la acción en tiempos de Diocleciano, con referencias a la Roma Imperial (Apro, campo marciano, Tíber, figuras o estatuas de Apolo y de Marte, anfiteatro...), pero la ambientación es propia de la España del siglo XVII, con una fusión de horizontes históricos en la que destaca la vida teatral contemporánea a la escritura de la pieza de los tres ingenios.

\section{DATACIÓN, REPRESENTACIONES Y RECEPCIÓN CRÍTICA}

Según datos recogidos por Jean Sentaurens (1105), en enero de 1644 la compañía de Antonio de Rueda representó en el corral de la Montería de Sevilla una comedia titulada San Ginés que obtuvo un gran éxito, pues se llevaron a cabo 10 representaciones, solo superado en el periodo 1640-1644 por El renegado del cielo de Cristóbal de Morales (Sentaurens 513). Aunque no se especifica el nombre de los poetas creadores, es de suponer que se trata de la comedia de El mejor representante, ya que la compañía de Antonio de Rueda llevaba también en el repertorio esa misma temporada El arca de Noé, representada pocas semanas después de San Ginés y que resulta ser la única otra comedia conocida escrita de consuno por los mismos tres ingenios, pieza publicada en 1665 en la Parte XXII de comedias nuevas escogidas, a nombre de Martínez, Rosete y Cáncer, en ese orden.

7 En su artículo Cattaneo sigue de cerca la acción argumental acto por acto, comparándola con la obra de Lope, por lo que no me detendré en estos aspectos aquí. Aparte del artículo citado en la bibliografía, hay que recordar que Cattaneo había dedicado ya a la comedia de los tres ingenios un interesante capítulo en los preliminares de su edición de Lo fingido verdadero (1992), en el que aportaba algunas citas significativas de la pieza dramática, ahondando en la comparación con la pieza lopesca (Vega 43-50). 
No se tiene referencia de ninguna otra representación durante el siglo XVII en la Península, ${ }^{8}$ aunque Manuel Antonio Arango (56) refiere la noticia de que en el día de Corpus Christi de 1675 se puso en escena en la ciudad de Lima. Elena Martínez Carro (119) señala igualmente una representación en el Corral del Príncipe en mayo de 1758 y tres en Valencia entre los años 1716 y 1744. A comienzos del siglo XIX se representó de nuevo en el Corral de la Cruz (19 de marzo, 19 de octubre y 25 de octubre de 1808; 16 de marzo de 1811) en una versión adaptada con el título de Hacer su papel de veras el mejor representante, de la que se conserva en la Biblioteca Histórica Municipal de Madrid un manuscrito, sin indicación de autoría, así como la partitura de Blas de Laserna con la música correspondiente para la representación. ${ }^{9}$

En cuanto a la recepción de la crítica pocas observaciones de sustancia pueden aducirse. En la introducción a su edición de Lo fingido verdadero, Menéndez y Pelayo parece valorar positivamente la pieza al sostener que

la [comedia] de los tres ingenios [...] conserva mucho de lo bueno de la obra de Lope, e introduce además ciertas modificaciones muy hábiles para regularizar la acción y preparar la conversión de Ginés, creando un nuevo e interesante personaje, el poeta cristiano Policarpo. Ticknor, aun declarando absurdo el argumento (con su habitual sequedad protestante), reconoce que este drama se lee con interés y en algunas partes con agrado. (LIII)

Elena Martínez Carro -en su monografía sobre uno de los ingenios colaboradores, Martínez de Meneses- afirma que esta comedia "ha sido enormemente valorada por la crítica" (332), aunque solo aporta el testimonio de Valbuena Prat, quien señaló que la pieza "refunde la citada de Lope [Lo fingido verdadero], pero con verdadera originalidad y espíritu diverso"..$^{10}$ Martínez Carro indica con acierto que "el metateatro es el protagonista de esta comedia hagiógrafa, que celebra al patrón de los comediantes" (333) y que "se puede con-

8 Sin embargo, Alejandro García-Reidy me hace saber, en comunicación personal, que consta en la base de datos CATCOM la noticia de una representación de San Ginés en Madrid durante la temporada teatral 1650-51, aunque no se ha hecho pública aún en la versión consultable en la web. Parece recogerla Cotarelo a partir de datos extraídos del archivo de Nuestra Señora de la Novena. Posiblemente se trataría de una representación de la compañía de Antonio García de Prado. Agradezco al profesor García-Reidy el avance de esta noticia.

9 Para mayor precisión en los datos y para acceder a la digitalización de este documento, ver http://www.cervantesvirtual.com/obra/hacer-su-papel-de-veras-el-mejor-representante/.

10 Martínez Carro refiere a Valbuena 385. 
siderar una de las mejores comedias en colaboración. La trama es perfectamente coherente y se eliminan los sucesos arbitrarios que aparecen en la comedia de Lope" (333).

Por su parte, $M$. Cattaneo no entra de lleno en cuestiones valorativas generales, prefiriendo situarla en el contexto de la evolución del teatro español del siglo XVII y en relación con las "transformaciones de Ginés" en otros teatros europeos:

Puesta dentro de una línea ideal que va de Lope al Calderón maduro, línea además de intensa evolución diacrónica, y que presupone diferencias en la modalidad de fruición, la "colaborada" remite a una insistida presencia de los grandes modelos (quizás no solo españoles), por otra parte modificando y desviando los trazos en una reelaboración en que la alternancia de las tres manos se percibe, a poco que ahondemos, de manera curiosa, aunque moderada, dando diferente relieve a los varios componentes de un paradigma depositado ya en la memoria colectiva, y con no banal diversificación de estilo. No es lugar este para entrar en el análisis puntual del texto, pero no dejaré de subrayar que parece digno de atención dentro del sistema teatral de la segunda mitad del siglo [...]. (267)

\section{ESTRUCTURA Y COMPOSICIÓN}

Desde el punto de vista de la estructura y de la composición de la comedia, es fundamental observar, por un lado, la disposición métrica y, por otro, y en relación con ella, la disposición espacio-temporal concretada en unidades que de modo moderno llamamos cuadros. Eso nos proporciona la primera visión de conjunto de cualquier pieza teatral, aunque no desarrollaremos especialmente esta cuestión ahora. La pieza de Cáncer, Rosete y Martínez consta de 3102 versos (1 258 en el primer acto, 942 en el segundo y 902 en el tercero). En el conjunto de las tres jornadas el romance (59\%) y la redondilla (27\%) son predominantes, aunque el $14 \%$ restante se caracteriza por una variada polimetría (soneto, décimas, quintillas, silva de pareados, sexta lira, canción) que, inserta entre las estrofas principales, conferiría en escena una gran diversidad rítmica a una comedia con numerosas intervenciones cantadas.

El mejor representante, San Ginés responde a una estructura muy equilibrada, con dos cuadros para el primer acto, tres para el segundo y tres para el tercero, muy propia del tipo de regularización que caracteriza la transición entre la época de Lope y la época de Calderón, acompañada de una reducción de 
tiempos y lugares de acción. En este caso, toda ella transcurre en Roma, a diferencia de Lo fingido verdadero, en la que en el primer acto se alternaba la acción en Mesopotamia y Roma. Cada acto discurre en una sucesión de horas que no va más allá de veinticuatro -en la primera jornada son solo dos o tres-, permitiéndose únicamente entre los actos saltos temporales imprecisos, que podemos calcular en unas pocas semanas.

Se aprecia una gran libertad imaginativa para crear nuevas situaciones que la distinguen de la pieza de Lope, que sin duda se tiene a la vista, sin volver a las fuentes hagiográficas (los Flores Sanctorum de Villegas o de Ribadeneyra) para encontrar punto de apoyo desde el que lanzarse a la imaginación de nuevos lances. En lo que se refiere a la trama principal que gira en torno a Ginés, destacan, por ejemplo, los siguientes puntos:

1) la introducción de un nuevo personaje, Policarpo, que tiene la doble condición de poeta y de presentador del cristianismo a Ginés;

2) un largo dúo entre Diocleciano y Ginés en octavas y romance, al comienzo de la jornada tercera;

3) numerosas variantes durante el proceso de conversión y martirio, en los actos segundo y tercero.

Además, se crean variadas situaciones nuevas de ambientación teatral y costumbrista, que tampoco pierden relación con el personaje de Ginés representante, es decir, no se realiza su inclusión presentando dos acciones separadas, mal o poco vinculadas entre sí, o mediante la técnica de introducir un entremés engastado que tuviera por sí mismo un valor autónomo y que, por lo tanto, pudiera extraerse sin perjuicio de la unidad compositiva.

Los tres ingenios toman igualmente dos decisiones básicas que distinguen su composición de la de Lope y que contribuyen a reforzar el aspecto de teatro como diversión festiva: la introducción de la comicidad y la ampliación del componente musical, sacro y profano, de extraordinaria presencia en la obra. ${ }^{11}$ En cuanto a la introducción de la comicidad el cambio es radical, pues

11 Por motivos de espacio, no se tratará en este artículo lo que Cattaneo ha descrito como "sottofondo sonoro che percorre tutta la commedia" (Vega 49), de gran interés por la alternancia musical sacro-profana y por su distribución bien calculada a lo largo de los tres actos, que parecería exigir la coordinación previa de los tres ingenios en este punto. También por motivos de espacio se habrán de dejar de lado cuestiones relativas a la autoría de cada acto y al proceso de colaboración, que presentan problemas de enjundia, sobre todo en relación con otra comedia editada en la misma Parte veinte y nueve de 1668, Píramo y Tisbe de Pedro Rosete. 
en Lo fingido verdadero quedaba excluida, salvo por levísimas intervenciones chistosas del criado Celio en una breve sección del acto primero. ${ }^{12}$ Es decir, Lo fingido verdadero no cuenta con personaje de gracioso, pero El mejor representante no solo tiene una figura de donaire, Julio, sino que introduce un segundo gracioso en el que merecerá la pena detenerse. Julio es un soldado camarada de Ginés y de Diocleciano, que ya se ve desde el comienzo de la acción que está en un segundo plano respecto a ellos. En cuanto Diocleciano es proclamado por sorpresa Emperador, y Ginés y Julio quedan solos, comienza a dibujarse su perfil de criado gracioso, hasta que en poco tiempo se confirma su función cuando Ginés y él entran en la compañía teatral de Enio, Ginés para representar papeles de galán y Julio los de gracioso. Precisamente para ganarse la confianza del autor, tienen que hacer una prueba como actores en la que Ginés recita unas décimas amorosas y él un soneto burlesco. A partir de ahí desarrolla su típico papel de donaire, adquiriendo una notable relevancia que no necesita ahora más comentario. ¿Pero quién es la figura del segundo gracioso y cuál es su función?

\section{Pocaropa, Pocarropa o Poca Ropa}

Al leer con atención la comedia, ya desde el anuncio de las "personas que hablan en ella" se repara en la presencia de un personaje peculiar. Junto a Ginés, Diocleciano, Camila y Marcela, que ya aparecían en la pieza de Lope, y al lado de otros caracteres con denominación de estirpe romana (Julio, Aurelio, Flora, Enio, Leonida) se lee el nombre de "Pocaropa". Este nombre me era ya familiar, porque al preparar la edición de El licenciado Vidriera de Agustín Moreto (impresa en 1653), en la segunda jornada aparecía una referencia a este personaje en una clara alusión del gracioso Gerundio a lo mal vestidos, desharrapados, que andaban él y su señor, Carlos:

Carlos De pesado andar no puedo.

GERUNDIO No por el vestido es, que tú y yo, si en eso topa, podemos ser Poca Ropa ${ }^{13}$ en un paso de entremés. (Moreto 1653, 323)

12 Se trata del cuadro tercero en Roma. Celio es criado del César Carino, dice varios comentarios jocosos "a la española" (v. 319) y hace algunas advertencias agudas entre los versos 315-80.

13 En el original de 1653 "poca ropa". 
Poca Ropa (o Pocaropa o Pocarropa) es el apodo de un actor del que se desconoce el nombre, que participó en la Loa para Un bobo bace ciento de Solís el Martes de Carnaval de 1656, donde Juan Rana hacía de Tiempo. Poca Ropa hace allí el papel de Carnestolendas y baila como Matachín, animando a los otros personajes a entrar en el baile. El DICAT, remitiéndose a Cotarelo, solo da como dato sobre Pocarropa la noticia de esta representación, pero se conocen algunos datos más sobre él, pues María Luisa Lobato había puesto una larga nota (Moreto 2003, 502) sobre esta máscara en su edición del teatro breve de Moreto, ya que aparece una referencia a él en la "Loa entremesada con que empezó en Madrid la compañía del Pupilo" y parece corresponderse con el nombre del Picarillo segundo del entremés Los gatillos, también de Moreto, representado en torno a 1661.

En el conjunto de El mejor representante Pocaropa tiene un papel muy secundario, pero activo en las tres jornadas. Destaca sobre todo el momento de su aparición en escena, cuando, jarra en mano y cantando, hace su autopresentación un pelín achispado, rasgo este, el de hacer de borracho, que parece uno de los más caracterizadores de su máscara junto con el aspecto desastrado que anuncia su nombre. ${ }^{14}$ Desde el punto de vista de la trama argumental, su papel adquiere importancia al ser el vínculo de Ginés y Julio con el mundo de los representantes, ya que caminando y caminando mientras hablan -conformándose lo que he denominado "espacio itinerante" (2005, 107-09)- han llegado al barrio de "los que las farsas recitan", identificado en la pieza como barrio del Mentidero, tal como se repetirá en dos ocasiones en la jornada tercera. Julio le ha preguntado a Ginés “¿Qué barrio es este?” y Ginés le responde:

No sé,

que, como ha tanto que estoy

ausente de Roma, soy

forastero en ella; ve

y señas del barrio toma. (vv. 515-19)

Se oye entonces "Dentro Pocaropa cantando"

Pocaropa Si no entiende el lenguaje

del baile el auditorio,

que por vida de Chápiro,

14 "Poca ropa. Modo de hablar con que se nota a alguno de pobre, o mal vestido: y se extiende a notar al que le falta alguna calidad de estimación” (Diccionario de Autoridades). 


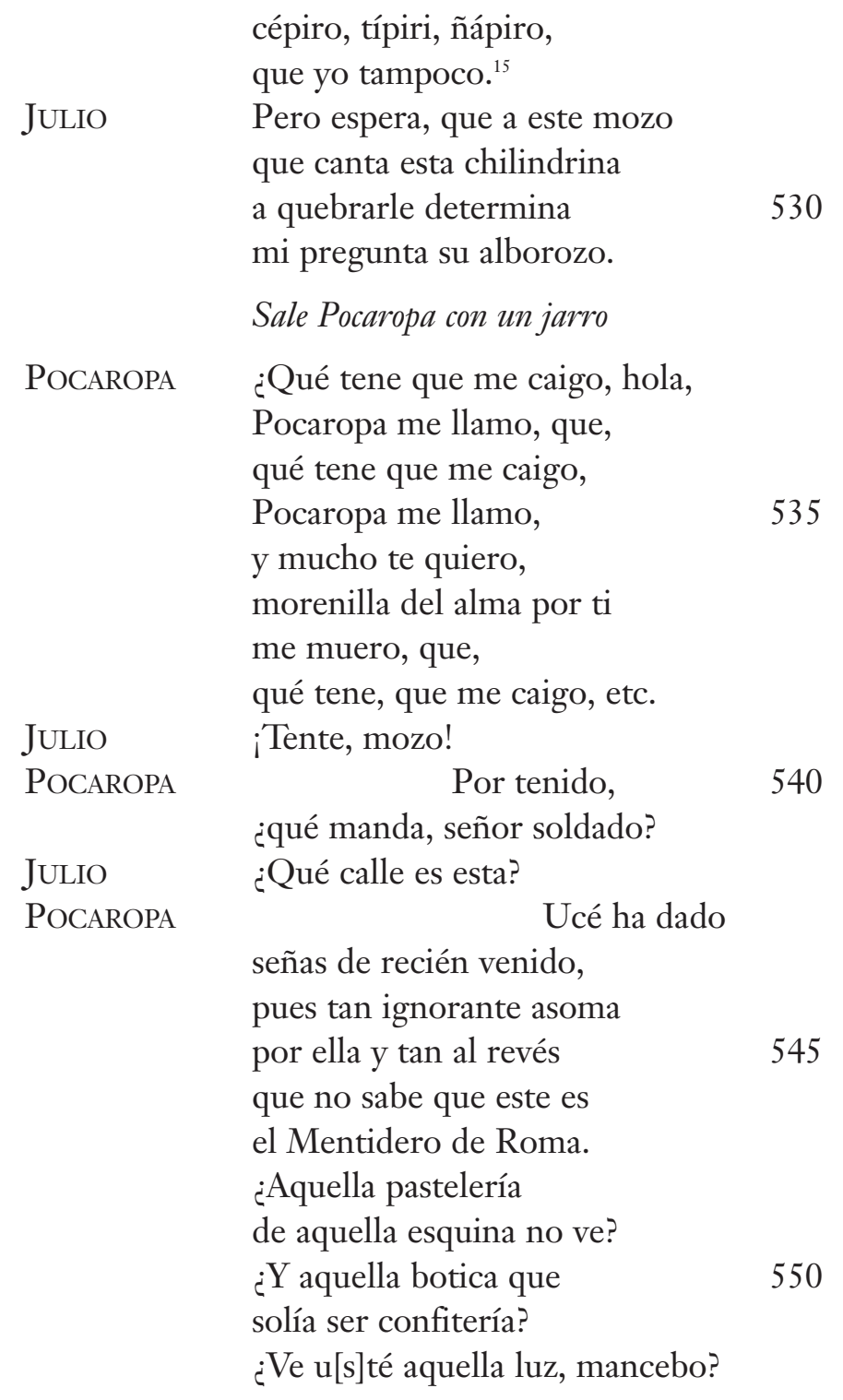

15 Tanto en las acotaciones como en el diálogo, salvo una vez, el nombre del personaje es "Pocaropa", quien anuncia su entrada en escena cantando una variante de la última estrofa del Baile del Chápiro, atribuido a Quiñones de Benavente, editada así por Lobato (318): "Si no entiende el lenguaje / del baile el auditorio / que ipor vida de Chápiro, / Zépiro, Nípero, Nápiro!, / que yo tampoco". Para la relación de estos versos con otros parecidos del entremés de El retablo de las maravillas, también de Quiñones, a los que hace referencia Lope en La noche de San fuan, ver Madroñal (132-43), quien edita igualmente el Baile del Chápiro. 
Julio Aquella es taberna.

POCAROPA

Pues

allí vivo donde bebo, de calles tan ignoradas, los que en ellas perseveran a ser de día os dijeran sus paredes almagradas.

Casas de posadas son cuantas veis, donde habitan los que las farsas recitan.

GINÉs Tú que tan buena razón nos das con tanto primor de aqueste gustoso trato, ¿quién eres?

POCAROPA

Mozo de hato

soy de agora de un autor que está haciendo compañía, que anda buscando un famoso primer galán y gracioso.

Julio Poco le falta, a fe mía.

Pocaropa Pero Aurelio, un gran señor, que favorece a la dama, ha enviado por dos de fama.

GINÉS ¿Quién es la dama?

POCAROPA

El mayor

asombro en quien se desvela la beldad, que a Roma espanta lo que representa y canta.

GINÉS ¿Cómo se llama?

POCAROPA Marcela. 580

GINÉS ¿Adónde vive el autor?

POCAROPA Aquí cerca.

Muy próxima en el tiempo a El mejor representante, San Ginés, la comedia de Rojas Zorrilla Abrir el ojo (I, vv. 426 y ss.), de tan fuerte ambientación madrileña, presenta a Don Clemente que quiere engañar a Don Julián diciéndole que va al Mentidero "a ensayar una comedia que ha escrito un amigo". Don 
Julián le contesta: "Voy allá / que en mi vida he visto ensayo", pero, como es un engaño, el lector o el espectador se quedan con las ganas de acompañarles realmente a la casa de un autor para presenciar un ensayo y ver a los comediantes en su salsa. Ese tipo de ambiente actoral se aprecia con gracia en varias piezas de teatro breve ya bien analizadas y editadas, ${ }^{16} \mathrm{y}$ en relación concreta con el ensayo hay un pasaje de mucho interés en una famosa obra de Mira de Amescua, El ejemplo mayor de la desdicha, que junto a otras escenas y alusiones han sido estudiadas en trabajos recientes por Jonathan Thacker y Alejandro García Reidy en el campo de la comedia, aunque sin remitirse a los ejemplos muy notables de la pieza de Cáncer, Rosete y Martínez. En este contexto El mejor representante funciona como una obra clave de la articulación entre el mundo de las loas, entremeses o mojigangas que giran en torno a episodios de la vida profesional de los comediantes y las comedias que en algún momento más o menos importante de su acción recurren al mismo tema. Como recordábamos antes en palabras de Elena Martínez Carro, "el metateatro es el protagonista de esta comedia hagiógrafa, que celebra al patrón de los comediantes" (333). Si la vida de Ginés sirve de continua reflexión sobre el tema del teatro del mundo (acciones de un hombre representadas ante otros hombres y ante Dios, espectador divino), en mayor medida sirve de medio para proponer una mirada al mundo del teatro, con sus poetas, autores, comediantes y comediantas, espectadores y espectadoras.

De la mano de Pocaropa, entonces, llegan al barrio del Mentidero Ginés y Julio, y con ellos los espectadores, comenzando una inmersión en el mundo del teatro ${ }^{17}$-en apariencia romano, pero en realidad bien español- que no terminará hasta el último verso de la comedia. Pocaropa les guiará hasta la casa del autor, en una de cuyas salas se dice que se habrán de hacer los ensayos, y de este modo sirve de nexo entre la acción inicial de la comedia -en la que aparece Diocleciano justo en los momentos previos a ser proclamado popularmente como Emperador- y el mundo teatral, en el que Ginés se encontrará

16 Ver en general el estudio de Sáez Raposo, con alusiones a numerosas piezas breves del siglo XVII. En particular, para los casos más importantes en el teatro de Moreto ("El vestuario", "El poeta”...) ver Sánchez-Imizcoz y las ediciones de las piezas correspondientes realizadas por Lobato (Moreto 2003); para el caso del entremés de "El ensayo" de Gil Enríquez, ver el trabajo de Cienfuegos y el de Londero.

17 Cattaneo había observado con acierto que "el encuentro con Pocaropa, un alegre borrachín que es criado en una compañía de teatro, permite el desarrollo de la peripecia y el cruce con el mundo teatral, que irrumpe presentado con vivacidad costumbrista, con sus ganancias, necesidades, herramientas, las peleas entre actrices, los problemas de la elección de las comedias" (263). 
con los otros personajes relevantes para el desarrollo del argumento: Policarpo, Aurelio y la dama Marcela.

\begin{tabular}{|c|c|}
\hline POCAROPA & $\begin{array}{l}\text { Caballero, } \\
\text { que luego este nombre hereda } \\
\text { quien me hace tanto favor, } \\
\text { esta noche puede ser } \\
\text { que un poeta ha de leer } \\
\text { una comedia al autor, } \\
\text { y siempre es fiesta precisa, } \\
\text { que si es de buena razón, } \\
\text { es cosa de admiración, } \\
\text { y si no, es cosa de risa. } \\
\text { Y entre tanto que se llama, } \\
\text { os podréis entretener } \\
\text { en oír, señor, y ver } \\
\text { los músicos y la dama, } \\
\text { y aun todas, pues han venido } \\
\text { a una gran cena que da } \\
\text { el señor Aurelio allá, } \\
\text { después de haberla leído. } \\
\text { Y el amante hará la fiesta } \\
\text { a mi parecer de fama, } \\
\text { que es muy rico, aunque la dama } \\
\text { no le da dél ni esta. }\end{array}$ \\
\hline GINÉS & ¿Podremos entrar allá? \\
\hline POCAROPA & $\begin{array}{c}\text { Bien podréis, si os llevo yo. } \\
{[\ldots]}\end{array}$ \\
\hline JULIO & $\begin{array}{l}\text { Pues señor } \\
\text { Pocaropa, guíe ucé, } \\
\text { pues nos hace esta mercé, } \\
\text { hacia casa del autor. }\end{array}$ \\
\hline
\end{tabular}

\section{LA METATEATRALIDAD}

$\mathrm{Al}$ acuñar el término "metatheatre" L. Abel abría en 1963 una riquísima vía de exploración al análisis teatral, que va mucho más allá del simple estudio de la pieza dramática representada dentro de otra pieza. El término fue cambiando 
sus límites conceptuales a lo largo del tiempo, adaptado proteicamente a diversas formas teatrales por investigadores con objetivos diferentes de los que inicialmente se había dado Abel. Si bien se ha reconocido el carácter pionero y seminal de su libro, no se ha ocultado igualmente la limitación de sus formulaciones, imprecisas a veces, contradictorias otras, insuficientes en cuanto se desciende a analizar la compleja casuística del teatro occidental en sus distintas manifestaciones "nacionales", francesa, inglesa, española o italiana, por ejemplo. No es de extrañar, entonces, que numerosos teóricos se hayan dedicado a tratar de precisar, concretar, corregir o reorientar la propuesta de Abel, lo que dio lugar, particularmente durante los años ochenta, a una amplia literatura crítica en la que destacan -junto a la abundante bibliografía en torno a Shakespeare y la estética metateatral- obras de Lucien Dällenbach, Georges Forrestier, Richard Hornby y Manfred Schmeling, referencias imprescindibles en la reflexión sobre el tema en las últimas tres décadas. La bibliografía es amplísima ya en la aplicación de este término y de su problematicidad al estudio del teatro del Siglo de Oro, como puede comprobarse, por ejemplo, en los diversos trabajos del número 5 de Teatro de palabras dedicado a esta cuestión (2011).

Somos, por lo tanto, conscientes de esa complejidad, pero puede ser ahora muy útil un acto de simplificación para abordar convenientemente la descripción y la explicación de la comedia de El mejor representante, mediante la distinción de estos niveles de metateatralidad: teatro dentro del teatro, teatro sobre el teatro, teatro en el teatro.

1) Por "teatro dentro del teatro" nos referimos a su sentido más fuerte o estricto, al hecho de que dentro de una obra dramática se represente una pieza o un fragmento de pieza teatral en la que se distinguen con claridad, en dos espacios bien marcados, unos personajes de la obra principal que hacen de actores de la pieza intercalada mientras otros personajes de la obra principal hacen de espectadores.

2) Por "teatro sobre el teatro" entendemos la reflexión o el comentario en los parlamentos de los personajes, por ejemplo:

a) en torno a la comparación de la vida humana con el teatro, principalmente según el tópico del gran teatro del mundo;

b) en torno a la composición de las obras teatrales y al carácter de los espectáculos;

c) en torno al arte del actor y a la interpretación.

3) Por "teatro en el teatro" entendemos la representación en escena de: 
a) el ambiente teatral en el vestuario o en la sala de los espectadores que precede, sucede al mismo tiempo o sigue a la representación de una pieza;

b) de la vida y del oficio de los actores;

c) y, muy especialmente, de la preparación del actor y de los ensayos.

Mientras en la comedia de Lope Lo fingido verdadero se aprecia un equilibrio de las tres modalidades (dos piezas intercaladas, con loa e intervención musical; un ensayo; amplia reflexión sobre el gran teatro del mundo y sobre la interpretación actoral, numerosas referencias a la vida y al oficio de los representantes), en la comedia de los tres ingenios se nota un énfasis muy marcado por la representación del teatro en el teatro, sin desatender las otras modalidades metateatrales.

Como prueba de la significación de lo que hablamos, a lo largo del itinerario dramático de San Ginés pueden identificarse los siguientes pasajes relevantes, de los que avanzamos algún fragmento textual a modo de ejemplo:

1) Breve relato en labios de Ginés de cómo en unos jardines junto al Tíber vio a una actriz en pleno acto de repetición-memorización-ensayo de los versos que leía en un papel (I, 91-172):

Muchas veces repetía, a lo que atendí, unos versos escritos en el papel, encomendarlos queriendo a la memoria, y de tantas como los dijo, sospecho que algunos dellos podré referirlos. Oíd atentos. $[\ldots]$

Así decían, que en referirlos me alegro: "Gentil galán, que en mi abril pretende flores tu mano, con las sombras de cristiano oscureces lo gentil. [...]"

2) Dos candidatos a actores -primer galán y gracioso- hacen su prueba ante el autor, lo que es llamado "dar muestra" (I, 911-1025). Ante la 
compañía el galán recita cuatro décimas y el gracioso un soneto burlesco.

ENIO

¿Quién anda ahí?

Julio Dos forasteros que andan buscando al señor autor.

ENIO ¿Qué es lo que ucedes demandan?

GINÉS Hemos sabido los dos

que a vuestra merced le faltan para hacer su compañía un galán, aunque le aguarda, y un gracioso, aunque le espera, y nosotros...

Aurelio Buena traza 920

de mozo.

MARCELA Famoso arte.

FLORA

LEONIDA

ENIO Y buena cara.

AURELIO ¿Qué partes?

GINÉS Yo, si os agrada, haré primeros galanes.

JULIO Yo graciosos.

AURELIO

ENIO

$$
\text { Yo me holgara, }
$$
que aunque he enviado por ellos, si a propósito se hallan, se han de recibir primero. Mandad, señor, que se haga lo que con todos, que es dar muestra, para que tomada la razón, sepamos todos.

Aurelio

MaRCELA Vaya.

JULIO

Plegue al cielo que conforme con su buen talle su gracia. Eso lo hará por estremo, y es de tan buena calaña que van de repente dél versos como de una vaca. 
GINÉs Dad licencia a esta señora que me escuche, porque haya sujeto a quien se le digan cuatro décimas.

MARCELA Lograrlas podéis, si en esto consiste.

Decid.

GINÉS

Atended.

JULIO No es nada. [...

ENIO Diga uced.

Julio Diré un soneto, pues cualquiera cosa basta para conocerlo; él 995 se hizo por una muchacha de setenta años, que diz que muchísimo se afeitaba.

FLORA No es muy malo el picarón. Julio Dice de esta suerte.

ENIO Vaya.

\section{$[\ldots]$}

3) Un poeta lee un pasaje de la comedia ante la compañía, en la casa del autor, concretamente en el lugar identificado como "sala" en la que se hacen los ensayos (I, 1057-136). Se introduce así la figura de Policarpo, de absoluta novedad respecto a Lo fingido verdadero, poeta de comedias religiosas como la de El cristiano bautizado que se representará ante el César y en la que Policarpo ejercerá también de apuntador.

Siéntanse todos en el suelo y Policarpo en una silla

AURELIO Siéntense todos.

ENIO

No hay cosa

como tenderse en la sala, pues no hay silla para todos.

GINÉS (Toda es confusión mi alma;

$[A p] \quad$. yo me siento.)

JULIO

Yo me tiendo.

ENIO Callen ahí. 
Aurelio

Algo vaya

curioso de la comedia.

ENIO Haced lo que Aurelio manda, pues todas vuestras comedias

que he recitado en las tablas

las he tomado por fe y han sido tan acertadas.

Policarpo (Supuesto que es el intento

de la comedia y la traza

1070

deleitar y aprovechar,

quiera Dios que en esta haya

con qué deleitar a todos

Ap.

y aprovechar algún alma.)

"El cristiano bautizado"

1075

es su título y pasadas

algunas cosas que aquí,

porque vos queréis, se callan,

sale el cristiano y al César,

que martirizar le manda,

1080

con católico fervor

le dice aquestas palabras.

(Se impriman agora aquí,

por vuestro divino amor,

en algún pecho, Señor.)

Ap. $\quad 1085$

AURELIO Proseguid, pues.

POLICARPO

Dice así:

Lea

"El que salvarte desea

antes de todo es forzoso

que con pecho religioso

la fe católica crea,

1090

la cual si inviolablemente

con integridad sincera

no la guardare cualquiera

perecerá eternamente.

[...] 
4) Ensayo fingido (II, 1470-532): en la sala de ensayos, Ginés y Marcela discuten sus penas de amor y al ser descubiertos por el celoso Aurelio, fingen que lo que decían era ensayo de la comedia, pero deslizándose de nuevo al recordarlo a un punto en el que se mezcla la realidad de su relación amorosa con la ficción de la comedia que van a representar.

MARCELA No me detengas, traidor, que aún escucharte no quiero.

GINÉs ¡Has de oírme!

MARCELA No he de oirte! ¿Tú con papel de otro dueño?

GINÉS Esto es verdad.

MARCELA No es verdad.

GINÉs Esto es cierto.

MARCELA No lo creo.

GINÉS ¡Mi bien!

MARCELA

GINÉS ¡Mi mal!

MARCELA Mi enemigo.

Sale Aurelio

AURELIO ¿Qué es aquesto? ¿De qué das voces? Y tú, ¿Cómo estás tan descompuesto?

Julio (¡Por Dios, que lo ha pescado!) decías y a muchas voces? "Esto es verdad, no lo creo", como que los dos reñíais, no sé si diga por celos.

MARCELA Sí, señor, por celos era.

Aurelio Pues, ¿cómo a mis ojos mesmos lo confesáis? ¡Vive Dios...!

Marcela No os enojéis, deteneos.

Estábamos ensayando, como otras veces solemos.

Ginés y yo un cierto paso 
muy apretado de celos

al tiempo que vos entrasteis,

y yo airada y él queriendo

satisfacerme, intentaba

detenerme, que el contexto

de la comedia dispone

que adore con grande estremo

a Ginés yo, digo yo,

la dama que represento.

1500

Aurelio Claro está, ya lo he entendido.

MarCELA Y Ginés me amaba tierno

un tiempo, digo Ginés,

el que introduce los versos,

que claro está...

Aurelio

Claro está

1505

que habláis de aquellos sujetos

que representáis los dos.

Los dos Sí, señor.

AURELIO Ya lo entiendo.

Marcela Hallábale yo un papel

de una dama, y él a intento

de satisfacerme...

GINÉS

Dije

que el papel no fue en su tiempo.

MARCELA Y le respondí: “¿Qué importa?

¿Cuándo es ofensa tenerlo

guardado?"

GINÉS

No es tal.

MARCELA

Sí es tal.

1515

GINÉS Esto es cierto.

MARCELA

GINÉS

$$
\text { Estotro es cierto. }
$$

MaRCELA

GINÉs

¡Eres crüel!

AurELIO

¡Tú eres falso!

¡Yo te adoro!

¡Deteneos!,

que lo decís tan al vivo

que pasa de fingimiento. 
MARCEla Como estamos ensayando...

$$
[\ldots]
$$

5) Marcela ensaya unas canciones acompañándose con el harpa, ante Aurelio, Ginés y Julio (II, 1630-95).

MarCELA Ya que sois tan cortesano

y queréis darme licencia, en el papel que yo hago

mañana canto unos versos

y tengo mal afirmado

el tono, y pues vos gustáis, servirá de festejaros, aunque un tono mal sabido

no suele ser agasajo, y a mí, que no le sé bien, me puede servir de ensayo. Julio, el harpa.

JULIO Aquí la tienes.

Marcela Pues porque veáis en el caso, Ginés, como ya sabéis, hace un rebelde cristiano

que sacrificar no quiere a los dioses soberanos y a martirizar le llevan, y yo estos versos le canto, imitando los embustes que ellos en el aire vago dicen que oyen cuando mueren, de ángeles imaginados. Floro el cristiano se llama, y dicen así, escuchadlos.

\section{Canta}

Pues que tan dichosa suerte el cielo te determina, camina, Ginés, camina, que esta tu vida es tu muerte. 
AURELIO Tened, que sin duda alguna 1665

la letra la habéis errado.

¿Esos versos no han de hablar

con aquel representado

cristiano que vos decís

que se llama Floro?

MARCELA

Es claro.

Aurelio Pues, ¿cómo Ginés dijisteis?

$$
[\ldots]
$$

6) Ensayo de Ginés solo en el Campo de Marte (1805-1910):

$$
[\ldots]
$$

¿Qué haré para divertirme?

Mas repasar determino

el papel; quizá mañana, como suele ser estilo,

me llevarán a palacio

a representar, y fío, si acierto a agradar al César, que perdone mi delito.

No repasaré aquel paso

en que deseo el bautismo,

porque ya le sé; va estotro

en que me dan el martirio.

Quiero ensayar las acciones

que signifiquen al vivo

1860

el papel que represento, en que ser cristiano finjo.

A mí me llevan atado

con oprobios infinitos

al martirio y yo, constante,

esto animoso les digo:

" Vengan tormentos, invente

la crueldad modos impíos

de castigos que amedrenten

el corazón más altivo!

¡Háganme dos mil pedazos, 
y a estos miembros divididos

no les dé el rigor lugar

de abrazarle con cariño!

Por vos mi dulce Jesús,

por vos todo lo permito,

por vos, buen Jesús, que todo

os lo debe el amor mío.

Fino amante, hermoso amante, con qué de gusto repito

vuestro nombre, Jesús bueno.

Jesús, Jesús, yo he vivido

como bárbaro anegado

en el golfo de mis vicios,

yo he sido vuestro contrario,

vuestro mayor enemigo

he sido yo. Recibidme,

buen Jesús...”, pero, ¿qué digo?

Esto no está en mi papel.

o confuso o divertido

me consentí arrebatar

de los afectos que finjo.

Quiero volverme a la parte

adonde me erré. Prosigo:

"Cristo es Dios, que vuestros dioses

son unos bultos fingidos.

Yo muero en esta verdad,

solo a Cristo sacrifico

el corazón que le adora.

$\mathrm{Ea}$, llevadme al suplicio."

$\mathrm{Y}$ en llegando aquí, me advierte

una voz que dulce trina...

\section{Dentro cantan}

Música Camina, Ginés, camina, que está tu vida en tu muerte.

$[\ldots]$ 
7) Representación de la "Comedia del cristiano bautizado" ante Diocleciano y su séquito (II, 2034-199). ${ }^{18}$

8) Ensayo de Ginés en la cárcel solo. ${ }^{19}$ Se pone en situación y prepara gestos de ojos y de arrebato para el momento cumbre de su ejecución (III, 2694-825):

\begin{tabular}{|c|c|}
\hline GINÉS & $\begin{array}{l}\text { Cuando hice con intento } \\
\text { de aclamaciones vanas } \\
\text { las comedias profanas, } \\
\text { ¿no me ensayaba atento, } \\
\text { mirándose advertido } \\
\text { cada acierto al espejo del oído? } \\
\text { Pues acción más fundada } \\
\text { será ensayar mi muerte } \\
\text { que no tiene, aunque acierte } \\
\text { en la primera jornada, } \\
\text { la gloria conseguida } \\
\text { quien yerra el postrer paso de la vida. } \\
\text { El teatro funesto } \\
\text { será el circo romano } \\
\text { y el concurso pagano } \\
\text { el pueblo que compuesto } \\
\text { de varias opiniones } \\
\text { o censure o aplauda mis acciones. } \\
\text { La corte soberana }\end{array}$ \\
\hline
\end{tabular}

18 Se corresponde con el final de la jornada segunda y es el punto culminante en toda obra sobre San Ginés, pues es el momento de la representación ante Diocleciano y su corte de una comedia ("teatro dentro del teatro") durante la que se produce en escena la conversión milagrosa de Ginés y su bautismo -aunque este se produce dentro-, mediante una intervención divina en forma de dos ángeles que es erróneamente interpretada por los espectadores de la corte romana como parte de la "Comedia del cristiano bautizado". Es imposible reproducir aquí ahora toda esta parte fundamental, que analizaré detalladamente en un próximo trabajo.

19 García Reidy realiza distinciones de mucho interés sobre las diferentes funciones estructurales del ensayo en la comedia española del Siglo de Oro que podrían aplicarse con provecho al estudio de El mejor representante. Habla, por ejemplo, García Reidy de "the performance of rehearsal as an integrated element within the plot in order to emphasize certain aspects of the play" (364), de "use of rehearsal as a process to examine the characters' emotions" (369) o del ensayo "as a way for characters to practice some type of situation or alternative identity that they will use later on in the play" (371). 
que me atienda aseguro,

pues diáfano y puro

de su imperio ventana

2715

el sol en curso lento

vidriera será con movimiento.

Allí es razón que arguya

que estará en silla de oro

de mártires el coro

y por ser fiesta suya

todos saldrán lucidos

de su líquida púrpura vestidos.

Hacellos es forzoso

cristiana competencia,

que estando en su presencia

será el yerro afrentoso,

pues ellos acertaron

cuando el mismo papel representaron.

Los aires veré hollados

de espíritus lucientes

que en visos transparentes

parecerán celados

desos velos sutiles,

antorchas que se asoman por viriles.

En su trono sentado

estará el Uno y Trino,

monarca más divino,

que es el que me ha mandado,

Sumo y Omnipotente,

que este particular le represente.

Tierra y cielo han de darme

una atención severa.

¡Qué auditorio me espera!

Pues empiezo a ensayarme,

que aunque el paso es tan fuerte

me va otra vida en acertar mi muerte.

De la impía ejecución

al aguardar los enojos 
pondré en el cielo los ojos.

¡Ah, qué buena es esta acción!

Y cuando el brazo levante

el ministro contra mí,

el arrebatarme allí

del afecto es importante.

Pero al llegar estos dos

trances, sangriento y crüel, ¿quién me apuntará el papel en que confieso a un Dios?

Sale una voz. Cantan.

\section{[MÚsICA]}

Dios.

A estos ocho pasajes habría que añadir otros numerosísimos en los que discuten las comediantas, se alude a episodios en el corral de comedias -como el de un vendedor de limas compinchado con una espectadora-, se comentan detalles del vestuario de los actores o de la utilería que cuelga en las paredes de la sala de ensayos, se hacen chistes sobre la actitud de los mosqueteros, etc., a la vez que va apareciendo una larga lista de términos relacionados con el oficio teatral: "saber en la uña un papel", "dar muestra", "versos de repente", "trasladar", "sacar por papeles", "repartir", "repasar", "decir o significar al vivo", "dar el pie", "representar propiamente", "representar un particular"... Como todo cabe en la comedia, también se incluye, siguiendo en esto el modelo de Lope en Lo fingido verdadero -aunque con la consiguiente variante en la reformulación- una versión a lo divino del mundo del teatro, muy propia de una comedia hagiográfica.

GINÉS

$[\ldots]$

pero desde aquí adelante,

siendo mi teatro mismo

la poca vida que ocioso

me dispensare el cuchillo,

representaré verdades,

y para este efecto elijo

otra mejor compañía.

Diocleciano Tus enigmas no descifro.

¿Otra compañía? 
GINÉS

En ella

2300

gano más altos partidos.

Diocleciano ¿Y cuál es?

GINÉS

Verás que toda

en breves rayos la pinto:

el poeta es David, que excede

a otros con pluma sucinta.

Lucas el teatro pinta,

porque en perspectiva quede.

Pedro es guardarropa y puede

su llave abrir y cerrar;

a su autor suele negar,

mas como amor le porfía

que vuelva a la compañía,

llora en oyendo cantar.

En esta farsa verás

que un ladrón la atención mueve,

pues con ser su papel breve

nadie pudo decir más.

Hace incrédulos Tomás,

Pablo un valiente que fue

triunfo de su misma fe.

Dama ha representado

Madalena y, aunque ha errado,

acierta en dándole el pie.

Embajadores Gabriel

hace en esta compañía

y como el Ave María

sabe siempre su papel.

Y Bartolomé es aquel

que, con gala celebrada,

por ver que a su autor agrada

traje diferente muda,

pues que la piel se desnuda

para la postrer jornada.

Hay, porque eleve el oído

con su harmonía perfecta, 
el harpa de un rey profeta.

Esta compañía ha sido,

César, la que yo he seguido.

El sumo autor Cristo es;

sabido para después

hay un paso entre los dos:

él hace auxilios de Dios,

yo martirios de Ginés.

Con todos estos ejemplos parece quedar demostrado el alto interés metateatral de la comedia de Cáncer, Rosete y Martínez, que a partir de ahora debería tenerse en cuenta como uno de los testimonios literarios más ricos del ambiente actoral del siglo XVII en España, a pesar de que la acción de la pieza transcurra en la Roma de Diocleciano. Sin embargo, creemos que su valor y su interés no se limitan a esta cuestión, como trataremos de mostrar en un próximo trabajo.

\section{OBRAS CITADAS}

Abel, Lionel. Metatheatre: A New View of Dramatic Form. New York: Hill and Wang, 1963.

Alviti, Roberta. I manoscritti autografi delle commedie del Siglo de Oro scritte in collaborazione: catalogo e studio. Firenze: Alinea Editrice, 2006.

Arango L., Manuel Antonio. Tema y estructura en el teatro del siglo XVI y XVII en Hispanoamérica y España. New York: Peter Lang, 2008.

Aszyck, Ursula. "Lo fingido verdadero de Lope de Vega y The Roman Actor de Philippe Massinger: puntos comunes y diferencias". En buena compañia: estudios en honor de Luciano García Lorenzo. Eds. Joaquín Álvarez Barrientos, Óscar Cornago Bernal, Abraham Madroñal Durán y Carmen Menéndez-Onrubia. Madrid: CSIC, 2009. 69-77.

Cáncer, Jerónimo, Pedro Rosete y Antonio Martínez. "El mejor representante, San Ginés". Parte veinte y nueve de comedias nuevas, escritas por los mejores ingenios de España. Madrid: Ioseph Fernández de Buendía, 1668. 188230.

Cattaneo, Mariateresa. “Transformaciones de Ginés, actor y mártir”. La comedia de santos: coloquio internacional, Almagro, 1, 2 y 3 de diciembre de 2006. Eds. Felipe B. Pedraza Jiménez y Almudena García González. Almagro: Ediciones de la Universidad de Castilla-La Mancha, 2008. 255-68. 
Cienfuegos Antelo, Gema. Edición anotada y estudio de dos entremeses y un baile dramático del siglo XVII: el Entremés famoso de la melancolía, el Baile de la comedia y El ensayo. Ottawa: University of Ottawa, 1996.

Diccionario biográfico de actores del teatro clásico español (DICAT). Ed. Teresa Ferrer Valls. Kassel: Reichenberger, 2008.

Diccionario de Autoridades (1726-1739). Madrid: Real Academia Española. 11 de marzo de 2019. <http://.frl.es/DA.html>.

García-Reidy, Alejandro. "Theatrical Voyeurism: Performing Rehearsal in the Spanish Comedia Nueva”. MLN 131.2 (2016): 356-77.

Lobato, María Luisa. La jácara en el Siglo de Oro: literatura en los márgenes. Madrid/Frankfurt am Main: TC/12/Iberoamericana/Vervuert, 2014.

Lobato, María Luisa, y Elena Martínez Carro, eds. Escribir entre amigos: Agustín Moreto y el teatro barroco. Madrid: Ayuntamiento de Madrid, 2018.

Londero, Renata. "Segundones áureos al ataque: el talento entremesil de Andrés Gil Enríquez (1636-1673)". Pictavia aurea. Actas del IX Congreso de la Asociación Internacional "Siglo de Oro". Eds. Alain Bègue y Emma Herrán Alonso. Toulouse: Presses Universitaires du Mirail, 2013. 947-54.

Mackenzie, Ann L. La escuela de Calderón: estudio e investigación. Liverpool: University Press, 1993.

Madroñal, Abraham. "Las circunstancias del estreno de La noche de san fuan (a propósito de los bailes que acompañaron a la comedia de Lope)". Monstruos de apariencias llenos: Espacios de representación y espacios representados en el teatro áureo español. Ed. Francisco Sáez Raposo. Bellaterra: Grupo de Investigación PROLOPE-Universitat Autònoma de Barcelona, 2011. 12748.

Martínez Carro, Elena. Antonio Martínez de Meneses: vida y obra. Madrid: FUE, 2006.

Matas Caballero, Juan, ed. La comedia escrita en colaboración en el teatro del Siglo de Oro. Valladolid: Ayuntamiento de Olmedo/Universidad de Valladolid, 2017.

Menéndez y Pelayo, Marcelino. "II. Lo fingido verdadero". Obras de Lope de Vega publicadas por la Real Academia Española. Tomo IV. Comedias de vidas de santos. Madrid: Sucesores de Ribadeneira, 1894. XXXIX-LIII.

Moreto, Agustín. "El Licenciado Vidriera". Quinta Parte de Comedias escogidas de los mejores ingenios de España. Madrid: Pablo de Val, 1653. 309-50.

Moreto, Agustín. Loas, entremeses y bailes. Ed. María Luisa Lobato. 2 vols. Kassel: Reichenberger, 2003. 
Oehrlein, Josef. El actor en el teatro español del Siglo de Oro. Madrid: Castalia, 1993.

Parte veinte y nueve de comedias nuevas, escritas por los mejores ingenios de España. Madrid: Ioseph Fernández de Buendía, 1668.

Rennert, Hugo Albert. The Spanish Stage in the Time of Lope de Vega. 1909. New York: Dover, 1963.

Rojas Zorrilla, Francisco de. Donde hay agravios no bay celos. Abrir el ojo. Eds. Felipe B. Pedraza Jiménez y Milagros Rodríguez Cáceres. Madrid: Castalia, 2005.

Rotrou, Jean. Le véritable Saint Genest. Eds. François Bonfils y Emmanuelle Hénin. Paris: Flammarion, 1999.

Rubiera, Javier. La construcción del espacio en la comedia española del Siglo de Oro. Madrid: Arco/Libros, 2005.

Rubiera, Javier. "Lope de Vega y el nuevo arte de escribir comedias de santos: una nueva mirada a Lo fingido verdadero". Symposium 70.4 (2016): 187-96.

Sáez Raposo, Francisco. "Del entremés a la comedia: itinerario de la metateatralidad". Teatro de palabras 5 (2011): 29-56.

Sánchez-Imizcoz, Ruth. "Algunos aspectos de la vida teatral a través de cuatro entremeses de Agustín Moreto". Comedia Performance 8.1 (2011): 78-112.

Sentaurens, Jean. Seville et le théâtre. De la fin du Moyen Âge à la fin du XVIIe siècle. Bordeaux: Presses Universitaires de Bordeaux, 1984.

Serrano Deza, Ricardo, Alfredo Hermenegildo y Javier Rubiera, eds. Teatro de palabras: monográfico sobre la metateatralidad 5 (2011).

Thacker, Jonathan. "Play Rehearsals on the Golden Age Stage". Artifice and Invention in the Spanish Golden Age. Eds. Stephen Boyd y Terence O'Reilly. Oxford: Legenda, 2014. 126-35.

Thacker, Jonathan. “«Para tiempos de veras / se ejercitan en las burlas»: Some Uses of Rehearsals on the Golden Age Stage". The Routledge Companion to Iberian Studies. Eds. Javier Muñoz Basols, Laura Lonsdale y Manuel Delgado. Abingdon: Routledge, 2017. 226-37.

Valbuena Prat, Ángel. El teatro español en su Siglo de Oro. Barcelona: Planeta, 1969.

Vega, Lope de. Lo fingido verdadero. Ed. Maria Teresa Cattaneo. Roma: Bulzoni, 1992. 